\title{
A comparison of indices of respiratory failure in ventilated preterm infants
}

\author{
N V Subhedar, A T Tan, E M Sweeney, N J Shaw
}

\begin{abstract}
Aim-To compare indices of respiratory failure in terms of their ability to predict adverse respiratory outcomes in preterm infants. The indices evaluated were: $(a)$ the alveolar-arterial oxygen tension difference $\left(\mathrm{A}-\mathrm{aDo}_{2}\right)$; (b) the ratio of arterial to alveolar oxygen tension (a/A ratio); (c) the oxygenation index $(\mathrm{OI})$; $(d)$ the fractional inspired oxygen concentration $\left(\mathrm{FIO}_{2}\right)$.
\end{abstract}

Methods-Details of respiratory support and arterial blood gas data in the first 24 hours of life were collected in ventilated infants below 34 weeks gestation. The worst single value of a particular index in the first 24 hours was chosen to quantify the severity of respiratory failure in each infant. Receiver operating characteristic curves were constructed and areas under the curve (AUC) calculated to compare the performance of the indices in predicting death from respiratory failure and/or the development of chronic lung disease (CLD).

Results-A total of 155 preterm infants were studied, of whom $35(23 \%)$ died primarily from respiratory failure and $\mathbf{5 3}$ of the 120 survivors (44\%) developed CLD. The overall performance of the four indices in predicting death from respiratory failure ranged from 0.77 (AUC for maximum $\mathrm{FIO}_{2}$ ) to 0.88 (AUC for minimum a/A ratio). The corresponding AUCs for gestational age and birth weight were 0.75 and 0.76 respectively. In contrast, demographic variables tended to perform better than indices of respiratory failure in predicting CLD/death.

Conclusions-There was no evidence of a significant difference between the performance of the a/A ratio, $\mathrm{A}-\mathrm{aDo}_{2}$, and OI in predicting adverse respiratory outcomes. Use of the OI is recommended because of its ease of calculation.

(Arch Dis Child Fetal Neonatal Ed 2000;83:F97-F100)

Care Unit, Liverpoo

Women's Hospital,

Liverpool, UK

N V Subhedar

A $T$ Tan

E M Sweeney

N J Shaw

Correspondence to:

Dr Subhedar, Neonata

Intensive Care Unit,

Liverpool Women's Hospital,

Crown Street, Liverpool

L8 7SS, UK

email:

nvsubhedar_lwh@yahoo.com

Accepted 24 March 2000
$\left(\mathrm{FIO}_{2}\right)$, which are closely related to each other and are operator dependent. ${ }^{1}$

Commonly used parameters of respiratory failure include the alveolar-arterial oxygen tension difference $\left(\mathrm{A}-\mathrm{aDO}_{2}\right)$, the ratio of arterial to alveolar oxygen tension (a/A ratio), and the oxygenation index (OI). ${ }^{2-4}$ Clinical trials of interventions for respiratory failure often use such parameters to select suitable infants, ${ }^{5}$ compare respiratory status in different groups after randomisation, ${ }^{67}$ and assess short term response. $^{89}$ Although most experience with these parameters has been in term infants, they are being used increasingly in preterm neonates. ${ }^{10}$ In term infants, parameters of respiratory failure have been used to predict outcome in infants with respiratory failure ${ }^{11}$; their value in preterm neonates with respiratory failure has not been systematically evaluated and remains unknown.

The aim of this study was to compare different parameters of respiratory failure in terms of their ability to predict adverse respiratory outcome in preterm infants.

\section{Methods}

Ventilated preterm infants below 34 completed weeks gestational age were considered eligible for the study if they met the following criteria.

(1) They had received mechanical ventilation within six hours of birth and until at least 24 hours of age.

(2) At least three arterial blood gas determinations had been performed within the first 24 hours of life from an indwelling arterial line.

(3) No major congenital anomalies were present.

Routine clinical management during the period of study included the prophylactic use of artificial surfactant (pumactant; Britannia Pharmaceuticals Ltd, Redhill, Surrey, UK) in all ventilated preterm babies. Two doses of surfactant were given to all babies, at birth and again 12 hours later. Mechanical ventilation was provided with conventional mechanical ventilators; high frequency ventilation was not used. Inhaled nitric oxide and natural surfactant (poractant alfa; Serono Pharmaceuticals Ltd, Middlesex, UK) were used in a few infants as part of randomised controlled trials running on the unit during the period of this study.

Supplemental oxygen was administered to maintain $\mathrm{PaO}_{2}$ between 50 and $70 \mathrm{~mm} \mathrm{Hg}$ in the acute phase of the respiratory illness. Subsequently, oxygen therapy was guided by pulse oximetry, aiming to maintain arterial oxygen saturation levels above $94 \%$. Infants who 
Table 1 Patient characteristics

\begin{tabular}{|c|c|c|c|}
\hline & Survivors $(n=120)$ & Deaths $(n=35)$ & $p$ Value \\
\hline Birth weight (g) & $1176(868-1479)$ & $872(730-942)$ & $<0.0001$ \\
\hline Gestation (weeks) & $29(26-30)$ & $27(25-27)$ & $<0.0001$ \\
\hline Male sex & $77(64)$ & $28(80)$ & 0.08 \\
\hline Caesarean section & $68(57)$ & $18(51)$ & 0.58 \\
\hline Antenatal steroids & $97(81)$ & $32(91)$ & 0.20 \\
\hline Apgar score at $5 \mathrm{~min}$ & $9(1-10)$ & $7(2-10)$ & 0.002 \\
\hline Surfactant & $120(100)$ & $35(100)$ & 1.0 \\
\hline Patient trigger ventilation & $10(8)$ & 0 & 0.12 \\
\hline $\operatorname{Max}$ PIP $\left(\mathrm{cm} \mathrm{H}_{2} \mathrm{O}\right)$ & $22(19-26)$ & $32(24-38)$ & $<0.0001$ \\
\hline $\operatorname{Max} \operatorname{PEEP}\left(\mathrm{cm} \mathrm{H}_{2} \mathrm{O}\right)$ & $4(4-4)$ & $4(4-5)$ & 0.001 \\
\hline $\operatorname{Max} \mathrm{MAP}\left(\mathrm{cm} \mathrm{H}_{2} \mathrm{O}\right)$ & $10.4(8.9-12.6)$ & $16.4(12.0-19.5)$ & $<0.0001$ \\
\hline $\mathrm{Max} \mathrm{PaCO}_{2}(\mathrm{~mm} \mathrm{Hg})$ & $48(41-53)$ & $55(47-73)$ & 0.0001 \\
\hline Max $\mathrm{FIO}_{2}$ & $0.68(0.46-0.86)$ & $1.0(0.98-1.0)$ & $<0.0001$ \\
\hline $\mathrm{Max} \mathrm{A}-\mathrm{aDo} \mathrm{O}_{2}(\mathrm{~mm} \mathrm{Hg})$ & $364(205-494)$ & $633(584-645)$ & $<0.0001$ \\
\hline Min $\mathrm{a} / \mathrm{A}$ ratio & $0.14(0.09-0.24)$ & $0.05(0.03-0.08)$ & $<0.0001$ \\
\hline Max OI & $10.0(5.6-19.1)$ & $38.8(22.0-98.9)$ & $<0.0001$ \\
\hline
\end{tabular}

Data are expressed as median (interquartile range) or $\mathrm{n}(\%)$.

PIP, peak inspiratory pressure; PEEP, peak end expiratory pressure; MAP, mean airway pressure; $\mathrm{A}-\mathrm{aDO}_{2}$, alveolar-arterial oxygen tension difference; a/A ratio, ratio of arterial to alveolar oxygen tension; OI, oxygenation index. remained agitated despite opiate sedation and appeared to breathe asynchronously were managed with patient triggered ventilation. Neuromuscular paralysis was reserved for infants with severe respiratory failure and asynchronous respiration. Caffeine citrate was used to facilitate weaning from mechanical ventilation and extubation directly into head box oxygen. A course of postnatal corticosteroids was considered in any infant who remained ventilator dependent with $\mathrm{FIO}_{2}$ above 0.30 beyond 7 days of age.

Details of respiratory support were gathered retrospectively from computerised blood gas data (which had been entered prospectively). For each arterial blood gas value entered within the first 24 hours of age, information about $\mathrm{PaO}_{2}, \mathrm{PaCO}_{2}, \mathrm{FIO}_{2}$, and mean airway pressure was collected at the same time, and values of $\mathrm{A}-\mathrm{aDO}_{2}, \mathrm{a} / \mathrm{A}$ ratio, and OI were calculated. ${ }^{1}$

Case notes were reviewed to obtain demographic details and outcome data. Respiratory outcomes collected included death and chronic lung disease, defined as oxygen dependency at 28 days and at 36 weeks postmenstrual age (CLD). Death certificates and/or postmortem examination reports were reviewed to classify the infants who died into two groups: (1) death primarily as a result of respiratory failure; (2) death from another cause, with co-existing respiratory disease. Infants in the first group were included in the study, and those in the second were excluded. Patient characteristics and respiratory support data were compared between groups of infants using univariate analysis (Mann-Whitney and $\chi^{2}$ tests for continuous and categorical data respectively).

Receiver operating characteristic (ROC) curves were constructed, and the area under the curve (AUC) calculated to assess the overall performance of different parameters of respiratory failure as predictors of $(a)$ death from respiratory failure and $(b)$ a combined adverse respiratory outcome of CLD and/or death from respiratory failure. ${ }^{12}$ The parameters evaluated were maximum $\mathrm{FIO}_{2}$, maximum $\mathrm{A}-\mathrm{aDo}_{2}$, minimum a/A ratio, and maximum OI within the first 24 hours of life. AUC was also calculated for birth weight and gestational age for comparison. Further discriminant analysis was performed by calculating the sensitivity, specificity, positive and negative predictive value, and positive and negative likelihood ratios for various thresholds of individual parameters. Statistical analysis was performed using the Arcus for Windows statistical package (Longman Software Publishing, Cambridge, UK).

\section{Results}

In total, 155 preterm infants met the study criteria. Of these, $35(23 \%)$ died primarily from respiratory failure, and 53 of the 120 survivors $(44 \%)$ had CLD. An additional 10 infants were receiving supplemental oxygen at 28 days, but not at 36 weeks postmenstrual age. The median age at death was 65 hours (interquartile range 16-384). Six infants were excluded because of "non-respiratory" deaths: three died from fungal septicaemia, two from Gram negative sepsis, and one from severe necrotising enterocolitis. The primary causes of "respiratory" death in infants included in the study were: respiratory distress syndrome in 25, pulmonary hypoplasia in three, and severe CLD in seven. Postmortem examinations were performed in 10 of the 35 infants who died.

A total of 1008 arterial blood gas determinations and corresponding ventilator settings were recorded; the median number of arterial blood gas determinations for each infant in the first 24 hours of life was seven (interquartile range five to eight). Table 1 shows the patient characteristics and respiratory data for surviving infants and those who died. Infants who died were significantly lighter and born after shorter gestation than those who survived. They also had significantly lower Apgar scores at five minutes. Respiratory support requirements and indices of respiratory failure were significantly higher during the first 24 hours in infants who ultimately died from respiratory failure. Maximum $\mathrm{PaCO}_{2}$ was also higher in this group. When all infants with an adverse respiratory outcome (CLD and/or death from respiratory failure) were compared with surviving infants without CLD, a similar overall pattern of differences in demographic and respiratory variables was observed (data not shown).

\section{PREDICTION OF DEATH FROM RESPIRATORY} FAILURE

Figure 1 shows the ROC curves for birth weight, maximum OI, and minimum a/A ratio for predicting death from respiratory failure.

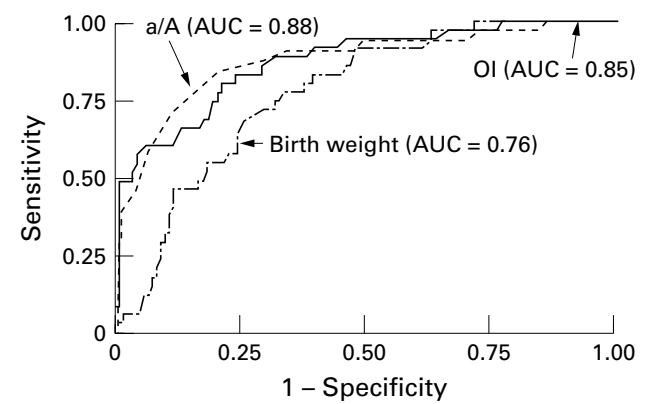

Figure 1 Receiver operating characteristic curves for prediction of death from respiratory failure. a/ $A$, ratio of arterial to alveolar oxygen tension; OI, oxygenation index; AUC, area under curve. 
Table 2 Performance of indices of respiratory failure for prediction of respiratory outcome

\begin{tabular}{|c|c|c|c|c|c|c|c|}
\hline & & \multicolumn{3}{|l|}{ Death } & \multicolumn{3}{|c|}{ CLD/death } \\
\hline & & $A U C$ & \multicolumn{2}{|c|}{$95 \% C I$} & \multicolumn{2}{|l|}{$A U C$} & $95 \% C I$ \\
\hline \multicolumn{2}{|c|}{ Gestational age } & 0.75 & \multicolumn{2}{|c|}{0.69 to 0.81} & \multicolumn{2}{|l|}{0.81} & 0.74 to 0.88 \\
\hline \multicolumn{2}{|c|}{ Birth weight } & 0.76 & \multicolumn{2}{|c|}{0.70 to 0.82} & \multicolumn{2}{|l|}{0.82} & 0.75 to 0.89 \\
\hline \multicolumn{2}{|c|}{ Maximum $\mathrm{FIO}_{2}$} & 0.77 & \multicolumn{2}{|c|}{0.71 to 0.82} & \multicolumn{2}{|l|}{0.66} & 0.57 to 0.75 \\
\hline \multicolumn{2}{|c|}{ Maximum OI } & 0.85 & \multicolumn{2}{|c|}{0.80 to 0.90} & \multicolumn{2}{|l|}{0.69} & 0.60 to 0.78 \\
\hline \multirow{2}{*}{\multicolumn{2}{|c|}{$\begin{array}{l}\text { Maximum A-aDo } \\
\text { Minimum a/A }\end{array}$}} & 0.87 & \multicolumn{2}{|c|}{0.82 to 0.92} & \multicolumn{2}{|l|}{0.69} & 0.60 to 0.78 \\
\hline & & 0.88 & \multicolumn{2}{|c|}{0.84 to 0.92} & \multicolumn{2}{|l|}{0.69} & 0.60 to 0.78 \\
\hline \multicolumn{8}{|c|}{$\begin{array}{l}\text { AUC, Area under the receiver operating characteristic curve; CLD, chronic lung disease; } \\
\text { A-aDO } \text { a }_{2} \text {, alveolar-arterial oxygen tension difference; a/A ratio, ratio of arterial to alveolar oxygen } \\
\text { tension; OI, oxygenation index. }\end{array}$} \\
\hline \multicolumn{8}{|c|}{$\begin{array}{l}\text { Table } 3 \text { Prediction of death from respiratory failure using minimum ratio of arterial to } \\
\text { alveolar oxygen tension }(a / A)\end{array}$} \\
\hline$a / A \leqslant$ & Sensitivity & Specificity & $\begin{array}{l}\text { Positive } \\
\text { predictive } \\
\text { value }\end{array}$ & $\begin{array}{l}\text { Negative } \\
\text { predictive } \\
\text { value }\end{array}$ & & $\begin{array}{l}\text { Positive } \\
\text { likelihood } \\
\text { ratio }\end{array}$ & $\begin{array}{l}\text { Negative } \\
\text { likelihood } \\
\text { ratio }\end{array}$ \\
\hline 0.02 & 0.11 & 0.99 & 0.80 & 0.79 & & 13.71 & 0.89 \\
\hline 0.06 & 0.63 & 0.93 & 0.73 & 0.90 & & 9.43 & 0.40 \\
\hline 0.10 & 0.91 & 0.66 & 0.44 & 0.96 & & 2.68 & 0.13 \\
\hline 0.14 & 0.94 & 0.51 & 0.36 & 0.97 & & 1.92 & 0.11 \\
\hline 0.18 & 0.94 & 0.32 & 0.29 & 0.95 & & 1.38 & 0.18 \\
\hline 0.22 & 0.97 & 0.26 & 0.28 & 0.97 & & 1.31 & 0.11 \\
\hline
\end{tabular}

Table 4 Prediction of death from respiratory failure using maximum oxygenation index (OI)

\begin{tabular}{lllllll}
\hline OI $\geqslant$ & Sensitivity & Specificity & $\begin{array}{l}\text { Positive } \\
\text { predictive } \\
\text { value }\end{array}$ & $\begin{array}{l}\text { Negative } \\
\text { predictive } \\
\text { value }\end{array}$ & $\begin{array}{l}\text { Positive } \\
\text { likelihood } \\
\text { ratio }\end{array}$ & $\begin{array}{l}\text { Negative } \\
\text { likelihood } \\
\text { ratio }\end{array}$ \\
\hline 10 & 0.94 & 0.52 & 0.38 & 0.97 & 1.97 & 0.11 \\
15 & 0.89 & 0.65 & 0.44 & 0.95 & 2.57 & 0.17 \\
20 & 0.80 & 0.77 & 0.52 & 0.93 & 3.48 & 0.26 \\
25 & 0.66 & 0.84 & 0.56 & 0.89 & 4.13 & 0.41 \\
30 & 0.60 & 0.91 & 0.68 & 0.88 & 6.78 & 0.44 \\
35 & 0.57 & 0.96 & 0.80 & 0.88 & 12.91 & 0.45 \\
\hline
\end{tabular}

Table 2 shows the AUC for various parameters. The AUC for gestational age and birth weight were similar to each other, at 0.75 and 0.76 respectively. Although the AUC for OI, $\mathrm{A}-\mathrm{aDO}_{2}$, and $\mathrm{a} / \mathrm{A}$ ratio tended to be higher, it was only the AUC for a/A ratio that was significantly different from those for birth weight and gestational age. The overall performance of the four indices of respiratory failure varied from 0.77 (AUC for maximum $\mathrm{FIO}_{2}$ ) to 0.88 (AUC for minimum a/A ratio). The AUC for $\mathrm{a} / \mathrm{A}$ ratio, OI, and $\mathrm{A}-\mathrm{aDO}_{2}$ tended to be larger than that for $\mathrm{FIO}_{2}$, but this was only statistically significant for the a/A ratio. There was no statistically significant difference between any of the other indices of respiratory failure. Tables 3 and 4 show the prognostic value of different thresholds of minimum a/A ratio and maximum OI within the first 24 hours for predicting death from respiratory failure.

\section{PREDICTION OF CLD/DEATH FROM RESPIRATORY} FAILURE

Table 2 shows the performance (AUC) of the various demographic variables and indices of respiratory failure in predicting CLD/death. The AUC for gestational age and birth weight were 0.81 and 0.82 , respectively. The indices of respiratory failure tended to perform worse overall, with areas under the curve between 0.66 for maximum $\mathrm{FIO}_{2}$ and 0.69 for the other three indices. There was no statistically significant difference between any of the indices of respiratory failure.

\section{Discussion}

In this study we have compared commonly used indices of hypoxaemic respiratory failure in terms of their ability to predict important adverse outcomes such as mortality from respiratory failure and CLD. The predictive performances of the three calculated parameters (a/A ratio, $\mathrm{A}-\mathrm{aDO}_{2}$, and $\mathrm{OI}$ ) were broadly similar; we were unable to identify a single measure of respiratory status that outperformed all the others. However, calculated parameters tended to be able to predict death from respiratory failure more effectively than a simple measure of respiratory failure $\left(\mathrm{FIO}_{2}\right)$ or demographic variables such as birth weight and gestational age.

In contrast, there was no equivalent benefit in the prediction of the combined adverse respiratory outcome of CLD/death; demographic variables tended to perform better than indices of respiratory failure in this respect. The most likely explanation for these observations is that the development of CLD is much more closely associated with birth weight and gestational age than with the severity of respiratory disease. Other studies have also shown a poor relation between severity of respiratory disease and the development of CLD, the causes of which are many. ${ }^{13} 14$

Indices of respiratory failure have been widely used as a measure of illness severity. However, calculation of these indices is not always straightforward, and a number of assumptions are necessary to simplify the equations used. ${ }^{2}$ These indices have now largely been replaced by the OI, which is generally preferred because it is easier to calculate and also incorporates a measure of ventilator pressures. ${ }^{1}$ We would recommend the use of the OI because of its simplicity and the lack of evidence suggesting superior performance using other parameters of oxygenation.

We studied a selected group of preterm infants who required respiratory support with conventional mechanical ventilation for at least 24 hours and had an arterial line in situ. We chose this group because it represents a typical population in whom indices of respiratory failure are used in clinical practice. However, our results cannot necessarily be extrapolated to predict outcome in other groups of newborn infants with respiratory disease or those managed using alternative ventilatory strategies.

The "worst" single value for each parameter was used to quantify respiratory status in the first 24 hours of life. Other summary measures that could have been used (to allow for repeated measurements in an individual) include the mean value or the "best" value during the same time period. Another approach would have been to test the performance of a parameter when persistently high or low over a period of time. We chose the worst single value because most clinicians are familiar with this type of threshold value, and a minimum level of respiratory illness severity can be assessed before the full 24 hour period has elapsed.

We have reported the predictive ability of the a/A ratio and OI at different severity thresholds 
in this study. This information may be useful in research by allowing selection of subjects for randomised controlled trials. For example, an a/A ratio of $\leqslant 0.06$ in a group of preterm infants managed with conventional ventilation would predict a risk of death from respiratory failure of $73 \%$, and at the same time correctly identify $90 \%$ of survivors. This information would be helpful in targeting potentially toxic new treatments to a population with a high risk of mortality. It would also allow calculation of study sample sizes according to respiratory illness severity at trial entry. In clinical practice, a knowledge of respiratory status may also help to guide optimal timing of the changeover from conventional treatment to "rescue" treatments such as high frequency ventilation and inhaled nitric oxide.

In summary, our results suggest that calculated indices of respiratory failure are useful in that they provide more information about the risk of death from respiratory failure than demographic variables such as birth weight or gestational age. We found that the performances of the OI, a/A ratio, and $\mathrm{A}-\mathrm{aDO}_{2}$ were similar in terms of predicting respiratory mortality and/or CLD. For clinical and research purposes, the OI is likely to be preferred because of its ease of calculation.

1 Boynton B, Hammond MD. Pulmonary gas exchange: basic principles and the effects of mechanical ventilation. In: Boynton BR, Carlo WA, Jobe AH, eds. New therapies for neonatal respiratory failure: a physiological approach. Cambridge: Cambridge University Press, 1994, 115-30.
2 Horbar JD. A calculator program for determining indices of neonatal respiratory distress syndrome severity. Am $\mathcal{F}$ Perineonatal respiratory
natol $1987 ; 4: 20-3$.

3 Gilbert R, Keighley J. The arterial/alveolar oxygen tension ratio. An index of gas exchange applicable to varying inspired oxygen concentrations. Am Rev Respir Dis 1974;109:142-5.

4 Bartlett RH, Toomasian J, Roloff D, Gazzaniga AB, Corwin AG, Rucker R. Extracorporeal membrane oxygenation (ECMO) in neonatal respiratory failure. Ann Surg 1986;204:236-44.

5 UK Collaborative ECMO Trial Group. UK collaborative randomised trial of neonatal extracorporeal membrane oxygenation. Lancet 1996;348:75-82.

6 Sinha S, Donn SM, Gavey J, McCarty M. Randomised trial of volume controlled versus time cycled, pressure limited ventilation in preterm infants with respiratory distress syn-
drome. Arch Dis Child Fetal Neonatal Ed 1997;77:F202-5.

7 Clark RH, Gerstmann DR, Null DM, Jr, deLemos RA. Prospective randomized comparison of high-frequency oscillatory and conventional ventilation in respiratory distress syndrome. Pediatrics 1992;89:5-12.

8 Leach CL, Greenspan JS, Rubenstein SD, et al. Partial liquid ventilation with perflubron in premature infants with severe respiratory distress syndrome. $N$ Engl $\mathcal{F}$ Med 1996;335:761-7.

9 Laubscher B, Greenough A, Kavvadia V, Devane SP. Response to nitric oxide in term and preterm infants. Eur f Pediatr 1997;156:639-42.

10 Van Meurs KP, Rhine WD, Asselin JM, Durand DJ, and the Preemie NO Collaborative Group. Response of premature infants with severe respiratory failure to inhaled nitric oxide. Pediatr Pulmonol 1997;24:319-23.

11 Ortega M, Ramos AD, Platzker AC, Atkinson JB, Bowman CM. Early prediction of ultimate outcome in newborn infants with severe respiratory failure. $f$ Pediatr 1988;113:744-7.

12 Hanley JA, McNeil BJ. The meaning and use of the area under a receiver operating characteristic (roc) curve. Radiology 1982;143;29-36.

13 Rojas MA, Gonzalez A, Bancalari E, Claure N, Poole C, Silva Neto G. Changing trends in the epidemiology and pathogenesis of neonatal chronic lung disease. 7 Pediatr 1995;126:605-10

14 Srisuparp, P, Khoshnood B, Corpuz M, Morgan S, Schreiber MD. Predictive power of oxygenation index for subsequent development of bronchopulmonary dysplasia in premature infants [abstract]. Pediatr Res 1999;45:227A. 